\title{
Curcumin reverses tobacco smoke-induced epithelial-mesenchymal transition by suppressing the MAPK pathway in the lungs of mice
}

\author{
ZHAOFENG LIANG ${ }^{1,2^{*}}$, RUI WU ${ }^{2,3^{*}}$, WEI XIE ${ }^{2,4}$, MINGMING ZHU ${ }^{2}$, CHUNFENG XIE $^{2}$, \\ XIAOTING LI $^{2}$, JIANYUN ZHU ${ }^{2}$, WEIWEI ZHU ${ }^{2}$, JIESHU WU ${ }^{2}$, SHANSHAN GENG ${ }^{2}$, \\ WENRONG XU ${ }^{1}$, CAIYUN ZHONG ${ }^{2,5}$ and HONGYU HAN ${ }^{6}$
}

\begin{abstract}
${ }^{1}$ Jiangsu Key Laboratory of Medical Science and Laboratory Medicine, School of Medicine, Jiangsu University, Zhenjiang, Jiangsu 212013; ${ }^{2}$ Department of Nutrition and Food Hygiene, School of Public Health, Nanjing Medical University, Nanjing, Jiangsu 211166; ${ }^{3}$ Chongchuanqu Market Supervision Administration, Nantong, Jiangsu 226006; ${ }^{4}$ Institute of Food Safety and Assessment, Jiangsu Provincial Center for Disease Control and Prevention, Nanjing, Jiangsu 210009; ${ }^{5}$ The Key Laboratory of Modern Toxicology, Ministry of Education, School of Public Health, Nanjing Medical University, Nanjing, Jiangsu 211166; ${ }^{6}$ Department of Clinical Nutrition, State Key Laboratory of Oncology in South China, Sun Yat-sen University Cancer Center, Guangzhou, Guangdong 510060, P.R. China
\end{abstract}

Received January 5, 2017; Accepted August 14, 2017

DOI: $10.3892 / \mathrm{mmr} .2017 .8028$

\begin{abstract}
Tobacco smoke is a major risk factor for lung cancer. Epithelial-mesenchymal transition (EMT) is decisive in cancer invasion and metastasis, and therefore promotes cancer progression. Mitogen-activated protein kinase (MAPK) pathways are implicated in various aspects of cancer development and progression, including the EMT process. The chemopreventive effect of curcumin on carcinogenesis has been reported in vivo and in vitro. The present study investigated tobacco smoke-induced alterations in the MAPK/activator protein-1 (AP-1) pathways, and pulmonary EMT changes in the lungs of mice, and further observed the chemopreventive effect of curcumin. The protein expression levels analyzed by western blot analysis demonstrated that 12 weeks of tobacco
\end{abstract}

Correspondence to: Dr Caiyun Zhong, Department of Nutrition and Food Hygiene, School of Public Health, Nanjing Medical University, 101 Longmian Avenue, Nanjing, Jiangsu 211166 , P.R. China

E-mail: cyzhong@njmu.edu.cn

Dr Hongyu Han, Department of Clinical Nutrition, State Key Laboratory of Oncology in South China, Sun Yat-sen University Cancer Center, 651 East Dongfeng Road, Guangzhou, Guangdong 510060, P.R. China

E-mail: hanhy@sysucc.org.cn

*Contributed equally

Key words: lung cancer, tobacco smoke, epithelial-mesenchymal transition, mitogen-activated protein kinase/activator protein-1 pathways, curcumin smoke exposure activated extracellular-signal-regulated kinase (ERK) 1/2, c-Jun N-terminal kinase (JNK) and p38 MAPK pathways, in addition to AP-1, in the lungs of mice, while reducing the activation of ERK5/MAPK pathways. The results also indicated that the mRNA and protein levels of the epithelial markers E-cadherin and zona occludens-1 were reduced following tobacco smoke exposure. Conversely, the expression levels of mRNA and protein for the mesenchymal markers vimentin and $\mathrm{N}$-cadherin were increased. Curcumin treatment inhibited tobacco smoke-induced MAPK/AP-1 activation, including ERK1/2, JNK and p38 MAPK pathways, and AP-1 proteins, and reversed EMT alterations in lung tissue. The results of the present study provide new insights into the molecular mechanisms of tobacco smoke-associated lung cancer and may open up new avenues in the search for potential therapeutic targets in lung tumorigenesis.

\section{Introduction}

Lung cancer is the most common type of cancer worldwide; the incidence and mortality rates of lung cancer are the highest among all human malignant tumors $(1,2)$. At present, lung cancer is the leading cause of cancer-associated mortality among men and women in China and western countries. It is estimated that the number of new cases of lung cancer reached 651,053 with a mortality rate of 529,153, in 2011 (3).

Tobacco smoke has an important role in the initiation and development of lung cancer. It is estimated that $~ 90 \%$ of lung cancer cases are associated with tobacco smoke (4), including $80 \%$ of all female and $90 \%$ of all male lung cancer cases (5). As a complex mixture, tobacco smoke contains $>6,000$ individual chemical constituents, among which 150 have been reported to exert toxicological effects, including the induction of free radicals and carcinogenic activities $(6,7)$. These 
ingredients are responsible for the carcinogenic potential of tobacco smoke, including the transformation and progression of cancer. Although progress has been made concerning the molecular mechanisms responsible for tobacco smoke-induced lung cancer development, the molecular pathogenesis requires further investigation.

Epithelial-mesenchymal-transition (EMT) is involved in embryonic development and tumorigenesis $(8,9)$. EMT is decisive in cancer invasion and metastasis. Evidence has indicated that EMT contributes to tumor progression by allowing cancer cells to avoid apoptosis and cellular senescence (10). During this process, cells progressively lose expression of membranous epithelial markers and acquire mesenchymal features (11). Tobacco smoke has been reported to promote EMT $(12,13)$. It has been identified that tobacco smoke-induced EMT may regulate the early events in carcinogenesis, including deprivation of cell-cell adhesion and apical-basal polarity, reduced expression of epithelial cadherin and upregulation of cell mobility (13). However, the potential mechanisms of tobacco smoke-induced EMT remain unclear.

The mitogen activated protein kinase (MAPK) cascade is a crucial signaling cascade involved in the transmission of stress-associated stimuli (14). This pathway also serves a key role in the development and progression of cancer (15). The classical MAPK pathway includes extracellular-signal-regulated kinase (ERK), c-Jun N-terminal kinase (JNK) and p38. Recent studies have reported that EMT may be controlled by ERK1/2, JNKs, p38 and ERK5 (16,17). Results from our previous studies have demonstrated that MAPK pathways are involved in tobacco smoke-induced EMT (18-21).

Curcumin [1,7-bis(4-hydroxy-3-methoxy phenyl)-1, 6-hepadiene-3,5-dione] is the principal active component of the plant Curcuma longa. For centuries curcumin has been used widely throughout India and South Asia in Ayurvedic medicine due to its nontoxic and beneficial properties, which include anti-inflammatory, antioxidant, wound healing and antiseptic properties (22-25). In addition, evidence has indicated that curcumin exhibits anticancer properties by affecting various biological pathways involved in apoptosis, mutagenesis, cell cycle regulation, oncogene expression, metastasis and angiogenesis (26-28). The ability of curcumin to inhibit carcinogenesis has been reported in vivo and in vitro (29). Our previous studies have demonstrated that tobacco smoke-induced alterations in EMT in the bladder and stomach tissues of mice are effectively attenuated by curcumin $(18,19)$. However, to the best of our knowledge, whether curcumin exhibits a protective effect on tobacco smoke-induced lung EMT is yet to be determined.

The present study aimed to investigate the effect of tobacco smoke on the activation of MAPK pathways and EMT in the lung in vivo, and further investigate the protective effects of curcumin against tobacco smoke-exposure. The results confirmed that curcumin exhibits a chemopreventive effect on tobacco smoke-induced lung EMT.

\section{Materials and methods}

Chemicals and reagents. Primary antibodies against phosphorylated (p)-ERK1/2 (cat. no. 4370S; 1:1,000), (p)-p38 (cat. no. 4511S; 1:1,000), (p)-JNK (cat.no. 9251S; 1:1,000), (p)-ERK5 (cat. no. 3371S; 1:500), (p)-c-Jun (cat. no. 9164S; 1:500), (p)-c-Fos (cat. no. 5348S; 1:500), Fos-like 2 activator protein-1 (AP-1) transcription factor subunit (Fra-2) (cat. no. 19967S; 1:1,000), E-cadherin (cat. no. 3195S; 1:1,000), N-cadherin (cat. no. 4061S; 1:500) and vimentin (cat. no. 3932S; 1:1,000) were obtained from Cell Signaling Technology, Inc. (Danvers, MA, USA). Zona occludens (ZO)-1 (cat. no. sc-8146; 1:500) primary antibody was purchased from Santa Cruz Biotechnology, Inc. (Dallas, TX, USA). The primary antibody for GAPDH (cat. no. 5014; 1:3,000) was from Biogot Technology Co., Ltd. (Nanjing, China). E-cadherin, ZO-1, N-cadherin, vimentin and GAPDH primers for reverse transcription-quantitative polymerase chain reaction (RT-qPCR) were synthesized according to published sequences from Invitrogen (Thermo Fisher Scientific, Inc., Waltham, MA, USA). Curcumin (purity, $>99 \%$ ) was purchased from Sigma-Aldrich (Merck KGaA, Darmstadt, Germany).

Animal and tobacco smoke exposure. A total of 52 male BALB/c mice (4-weeks-old; weight, 18-22 g) were purchased from the Animal Research Center of Nanjing Medical University (Nanjing, China). All mice were allowed one week acclimatize to circumstances prior to experimental exposure. Mice were raised in polypropylene cages at $22 \pm 0.5^{\circ} \mathrm{C}$ and $40-60 \%$ relative humidity with a 12 -h light/dark cycle, and water and basal diet were provided ad libitum. All mice procedure protocols were approved by the Animal Care and Welfare Committee of Nanjing Medical University.

Mice were randomly divided into tobacco smoke-exposure and control groups ( $n=10 /$ group). The tobacco smoke-exposure group was treated with tobacco smoke for $6 \mathrm{~h}$ daily for 12 weeks. The control group animals were exposed to filtered air. Mice in the tobacco smoke group were exposed to tobacco smoke in a smoking apparatus designed by the authors. A smoke machine was used to combust filterless commercial cigarettes (12 $\mathrm{mg}$ tar and $1.1 \mathrm{mg}$ nicotine per cigarette, Hongtashan brand; Hongta Group, Yuxi, China) to generate tobacco smoke. The smoke machine pumped the cigarette smoke regularly from burning filterless cigarettes ( $5 \mathrm{~min} /$ cigarette). The target concentration of smoke was delivered to whole-body exposure chambers in total particulate matter of $85 \mathrm{mg} / \mathrm{m}^{3}$. The components were monitored and characterized as: Carbon monoxide $\left(14.72 \pm 2.89 \mathrm{mg} / \mathrm{m}^{3}\right)$ and total particulate matter TPM $\left(0 \mathrm{mg} / \mathrm{m}^{3}\right)$ for the control group; and carbon monoxide $\left(184.07 \pm 23.51 \mathrm{mg} / \mathrm{m}^{3}\right)$ and TPM $\left(83.53 \pm 5.63 \mathrm{mg} / \mathrm{m}^{3}\right)$ for the tobacco smoke exposure group. Mice were sacrificed at the end of the final tobacco smoke exposure, and the lung tissues were isolated, frozen and stored at $-80^{\circ} \mathrm{C}$ until analysis.

Curcumin treatment of mice. Doses were selected based on those employed by previous studies involving the treatment of mice with curcumin, which were 50 or $100 \mathrm{mg} / \mathrm{kg}$ body weight (BW) per day in animal models $(30,31)$. BALB/c mice were randomly assigned into the following four groups ( $n=8$ per group): Filtered air group, in which mice were exposed to filtered air and under a controlled diet; a tobacco smoke-exposed group, in which mice were exposed to tobacco smoke and under a controlled diet; tobacco smoke + curcumin $50 \mathrm{mg}$ group, in which mice were exposed to tobacco smoke and under a controlled diet supplemented with curcumin at a 
dose of $50 \mathrm{mg} / \mathrm{kg} \mathrm{BW} / \mathrm{day}$; and tobacco smoke + curcumin $100 \mathrm{mg}$ group, in which mice were exposed to tobacco smoke and under a controlled diet supplemented with curcumin at a dose of $100 \mathrm{mg} / \mathrm{kg} \mathrm{BW} /$ day. The mice were exposed to filtered air or tobacco smoke at a target concentration of $85 \mathrm{mg} / \mathrm{m}^{3}$ total particulate matter for $6 \mathrm{~h}$ daily for 12 weeks. Dietary consumption levels and body weight were measured and recorded every 3 days to determine the administration dosages of curcumin. The diets were prepared weekly for each group. At the end of the exposure, mice were sacrificed and the lung tissues were frozen and stored at $-80^{\circ} \mathrm{C}$ until analysis.

Western blot analysis. Western blot analyses were performed following standard procedures. Briefly, lung tissues were lysed (lysate buffer, $5 \mathrm{mmol} / 1$ EDTA; $50 \mathrm{mmol} / 1$ Tris $\mathrm{pH}$ 7.5, 1\% sodium dodecyl sulfate (SDS), $10 \mu \mathrm{g} / \mathrm{ml}$ aprotinin, $1 \%$ sodium deoxycholate, $1 \%$ NP-40, $1 \%$ Triton-X 100, 1 mM phenylmethylsulfonyl fluoride, $10 \mu \mathrm{g} / \mathrm{ml}$ leupeptin) and the lysate supernatants were obtained by centrifugation at $12,000 \mathrm{x} \mathrm{g}$ for $20 \mathrm{~min}$ at $4^{\circ} \mathrm{C}$ and the pellets were discarded. A BCA Protein assay kit (Pierce; Thermo Fisher Scientific, Inc.) was used to measure protein concentrations. Electrophoresis was performed to fractionate $50 \mu \mathrm{g}$ proteins by $7.5-10 \%$ SDS-PAGE. Subsequently, proteins were transferred onto polyvinylidene fluoride membranes (EMD Millipore, Billerica, MA, USA). Following blocking with 5\% non-fat milk for $1 \mathrm{~h}$ at room temperature, membranes were incubated with primary antibodies overnight at $4^{\circ} \mathrm{C}$, followed by incubation with horseradish peroxidase-conjugated secondary antibody (cat. no. 00001-2; 1:5,000) from Biogot Technology Co., Ltd. (Nanjing, China) for $1 \mathrm{~h}$ at room temperature. The membranes were developed with SignalFire Elite ECL Reagent (Cell Signaling Technology, Inc.). GAPDH served as the loading control. Image J k 1.45 (National Institutes of Health, Bethesda, MD, USA) was used to perform densitometric analysis on protein bands.

RT-qPCR analysis. Total RNA was extracted from the mouse lung tissues using RNAiso Plus (Takara Bio, Inc., Otsu, Japan), according to the manufacturer's protocol. Subsequently, $2 \mu \mathrm{g}$ purified total RNA was reverse transcribed to cDNA using PrimeScript RT Master mix (Takara Bio, Inc.) according to the manufacturer's protocol. The RT reaction was performed as follows: $37^{\circ} \mathrm{C} 15 \mathrm{~min}, 85^{\circ} \mathrm{C} 5 \mathrm{sec}$, and hold at $4^{\circ} \mathrm{C}$, using AMV Reverse Transcriptase (Promega Corporation, Madison, WI, USA). qPCR was performed according to the manufacturer's protocol: Initial denaturation at $95^{\circ} \mathrm{C}$ for $30 \mathrm{sec}$, followed by 40 cycles of $95^{\circ} \mathrm{C}$ for $5 \mathrm{sec}, 60^{\circ} \mathrm{C}$ for $30 \mathrm{sec}, 72^{\circ} \mathrm{C}$ for $30 \mathrm{sec}$ using the SYBR ${ }^{\circledR}$ Premix Ex Taq $^{\mathrm{TM}}$ II (Takara Bio, Inc.) and an ABI prism 7300 system (Applied Biosystems; Thermo Fisher Scientific, Inc.). The primers (Invitrogen; Thermo Fisher Scientific, Inc.) used were as follows: E-cadherin forward, 5'-TCGACACCCGATTCAAAGTGG-3' and reverse, 5'-TTC CAGAAACGGAGGCCTGAT-3'; ZO-1 forward, 5'-GCA GCCACAACCAATTCATAG-3' and reverse, 5'-GCAGAC GATGTTCATAGTTTC-3'; vimentin forward, 5'-CCTTGA CATTGAGATTGCCA-3' and reverse, 5'-GTATCAACCAGA GGGAGTGA-3'; N-cadherin forward, 5'-ATCAAGTGCCAT TAGCCAAG-3' and reverse, 5'-CTGAGCAGTGAATGTTG TCA-3'; GAPDH forward, 5'-GCTGCCCAACGCACCGA
ATA-3' and reverse, 5'-GAGTCAACGGATTTGGTCGT-3'. The specificity of the PCR products was confirmed using melting curve analysis. Relative gene expression levels, normalized to GAPDH expression, were calculated by a comparative threshold cycle $(\mathrm{Cq})$ method using the formula $2^{-(\Delta \Delta \mathrm{Cq})}(32)$. Each sample was performed in triplicate.

Statistical analysis. Statistical differences were analyzed using one-way analysis of variance for comparison of statistical differences among multiple groups and the Fisher's least significant difference test. Unpaired Student's t-test was also used for comparisons between two groups. SPSS software version 16.0 (SPSS, Inc., Chicago, IL, USA) was used to perform statistical analysis. Data are presented as the mean \pm standard deviation. $\mathrm{P}<0.05$ was considered to indicate a statistically significant difference.

\section{Results}

Tobacco smoke induces EMT alterations in lung tissues of mice. Tobacco smoke is a major risk factor for lung cancer. EMT has important functions in various types of cancer, including lung cancer, and tobacco smoke-induced EMT is implicated in tobacco smoke-associated malignant transformations. To determine whether alterations in EMT were induced by tobacco smoke in an animal model, mice were exposed to tobacco smoke for 12 weeks, and the expression of the epithelial markers E-cadherin and ZO-1, and the mesenchymal markers vimentin and $\mathrm{N}$-cadherin, in lung tissues was examined. Tobacco smoke exposure led to reduced E-cadherin and ZO-1 mRNA levels in mice lungs, and the mRNA expression of vimentin and $\mathrm{N}$-cadherin was increased, compared with the filtered air-treated group, as determined by RT-qPCR (Fig. 1A). Western blot analysis further revealed that tobacco smoke exposure also led to similar effects at the protein level, with downregulated E-cadherin and ZO-1 protein expression levels, and upregulated $\mathrm{N}$-cadherin and vimentin protein expression levels compared with the filtered air-treated group (Fig. 1B and C).

Tobacco smoke activates pulmonary MAPK/AP-1 pathways in mice. The expression levels of p-ERK1/2, p-JNK, p-p38 and p-ERK5 were also measured to establish whether the observed tobacco smoke-induced pulmonary EMT alterations are associated with changes in MAPK activation. The results demonstrated that tobacco smoke increased the activation of ERK1/2, JNK and p38 pathways, while it suppressed the ERK5 MAPK pathway (Fig. 2A). Additionally, tobacco smoke exposure upregulated the levels of p-c-Fos, p-c-Jun and Fra-2, which are indicators of the AP-1 activation status (Fig. 2B).

Curcumin reverses tobacco smoke-induced EMT alterations in the lungs of mice. To investigate whether curcumin may reverse tobacco smoke-mediated EMT in the mouse lung, mice were treated with curcumin (50 or $100 \mathrm{mg} / \mathrm{kg} \mathrm{BW}$ ) and exposed to tobacco smoke for 12 weeks. Tobacco smoke-induced alterations in the mRNA and protein expression EMT markers were subsequently investigated. As expected, the results demonstrated that curcumin, particularly $100 \mathrm{mg} / \mathrm{kg} \mathrm{BW}$ curcumin, treatment attenuated the tobacco smoke-induced 

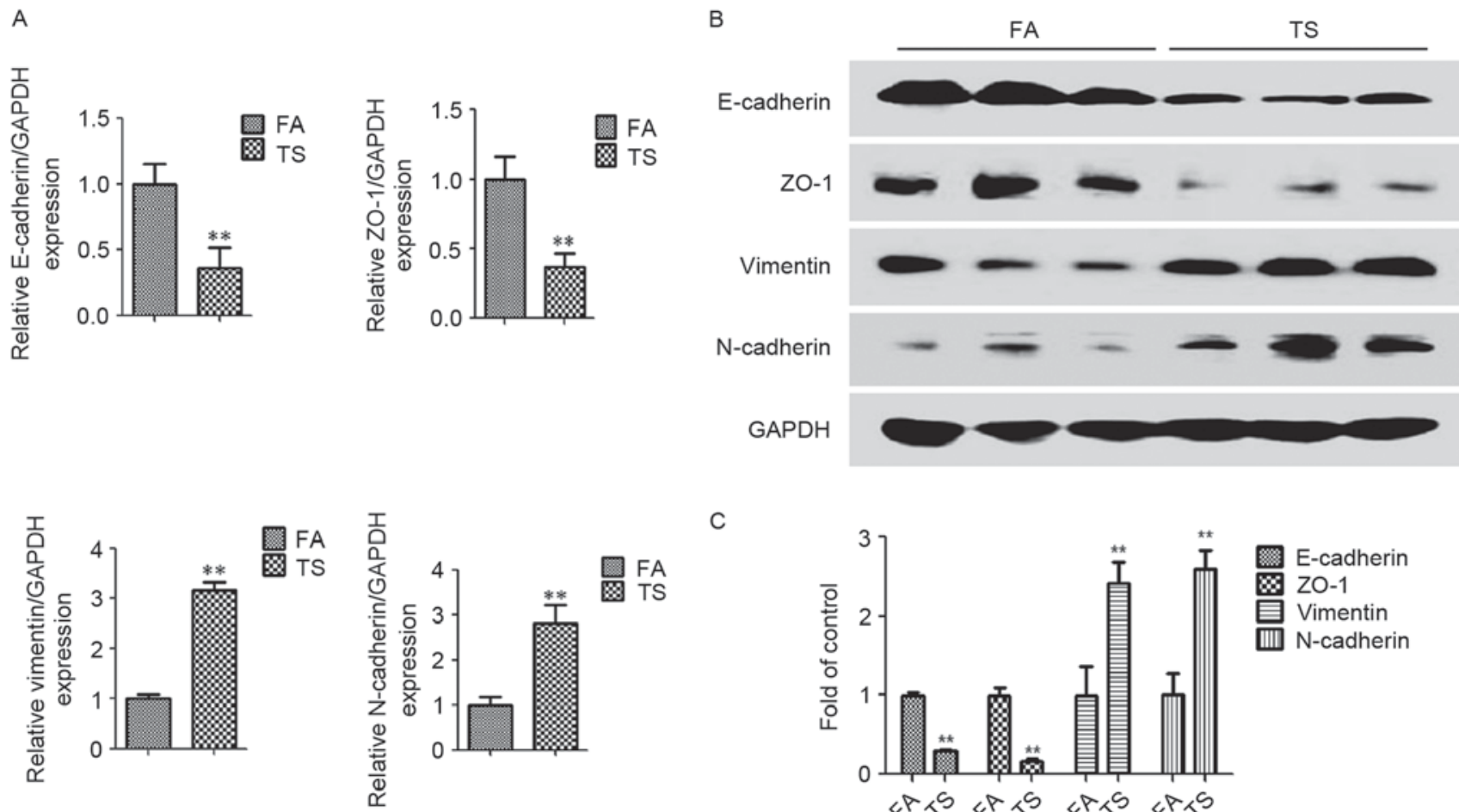

C

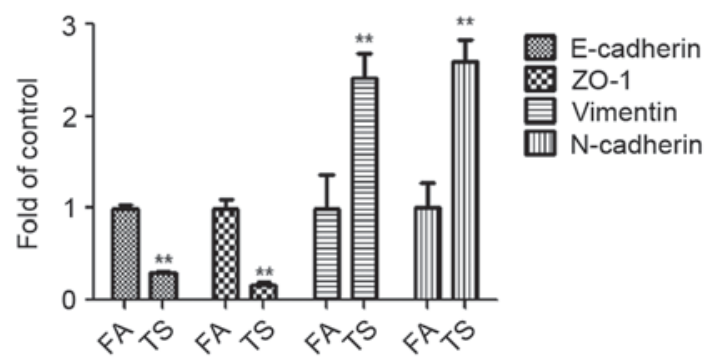

Figure 1. Following exposure to TS for 12 weeks, TS induced alterations in the expression of epithelial-mesenchymal transition markers in the lungs of mice. (A) TS reduced E-cadherin and ZO-1 mRNA levels, and increased mRNA levels of vimentin and N-cadherin, as determined by reverse transcription-quantitative polymerase chain reaction. (B) TS downregulated the protein levels of E-cadherin and ZO-1, and upregulated the protein levels of vimentin and $\mathrm{N}$-cadherin in the lungs of mice. GAPDH was used as a loading control for western blotting. (C) Densitometric analyses of western blotting. Data are presented as mean \pm standard deviation. ${ }^{* *} \mathrm{P}<0.01$ vs. FA. TS, tobacco smoke; $\mathrm{ZO}$, zona occludens; FA, filtered air.

A

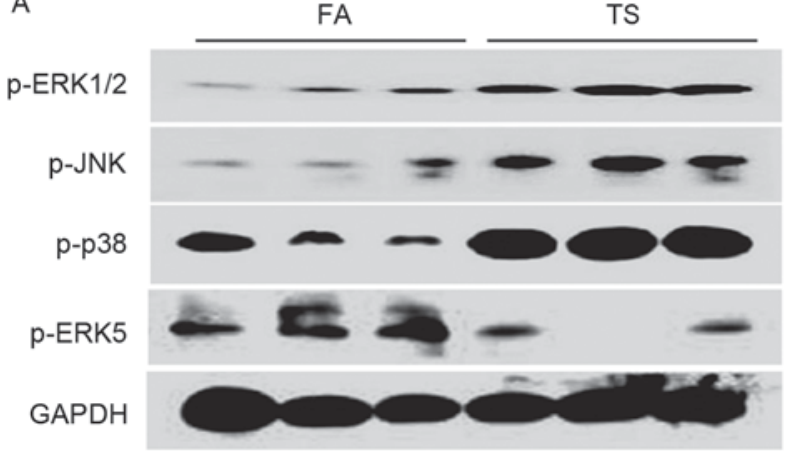

B

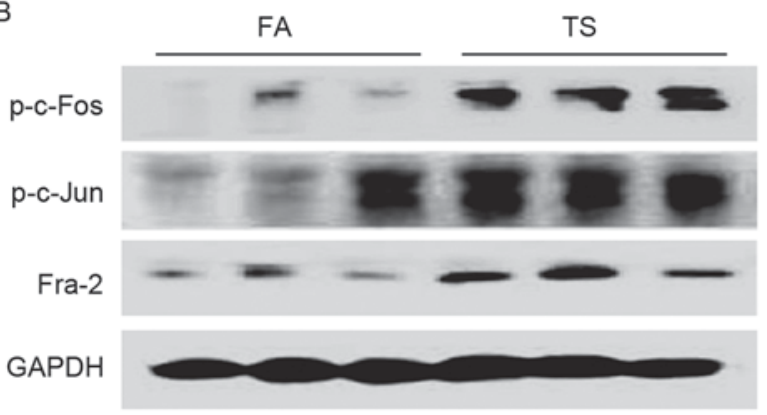

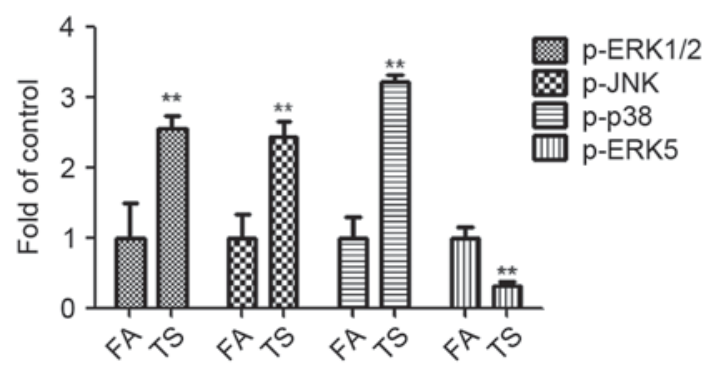

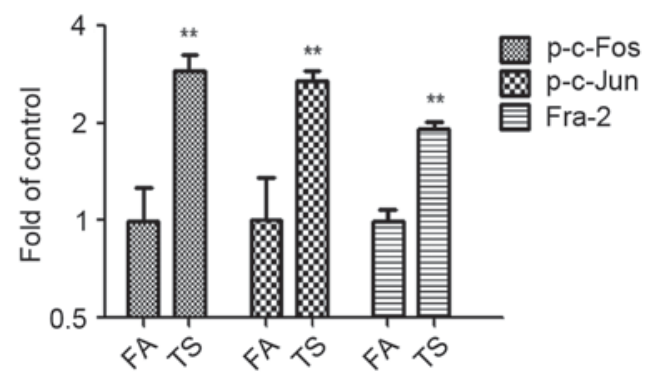

Figure 2. TS increased MAPK activation in the lungs of mice. (A) p-ERK1/2, p-JNK, p-p38 and p-ERK5 expression by western blotting. (B) Western blotting results for p-c-Fos, p-c-Jun and Fra-2. Data are presented as the mean \pm standard deviation. ${ }^{* *} \mathrm{P}<0.01 \mathrm{vs}$. FA. GAPDH was used as a loading control. TS, tobacco smoke; MAPK, mitogen-activated protein kinase; p-, phosphorylated-; ERK, extracellular-signal-regulated kinase; JNK, c-Jun N-terminal kinase; Fra-2, Fos-like 2 activator protein-1 transcription factor subunit; FA, filtered air.

decreases in E-cadherin and ZO-1 expression, and increases in vimentin and $\mathrm{N}$-cadherin expression. These results indicate that curcumin reversed tobacco smoke-induced alterations in pulmonary EMT in vivo (Fig. 3). 
A
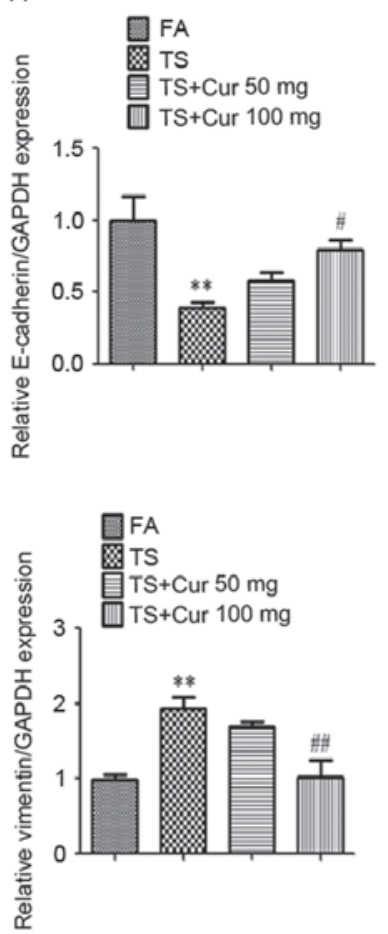

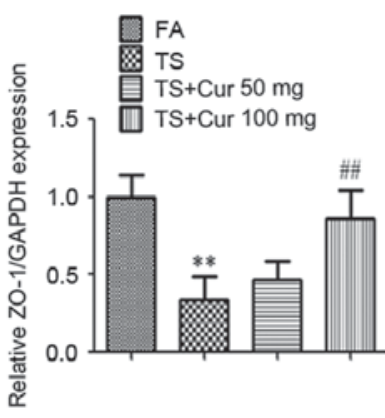

B

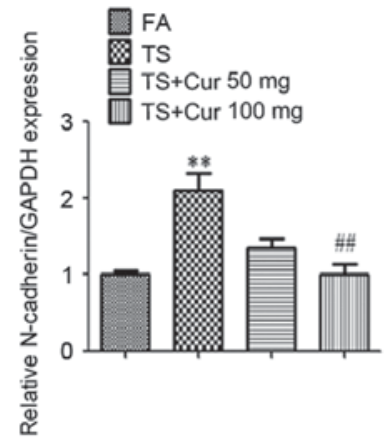

C
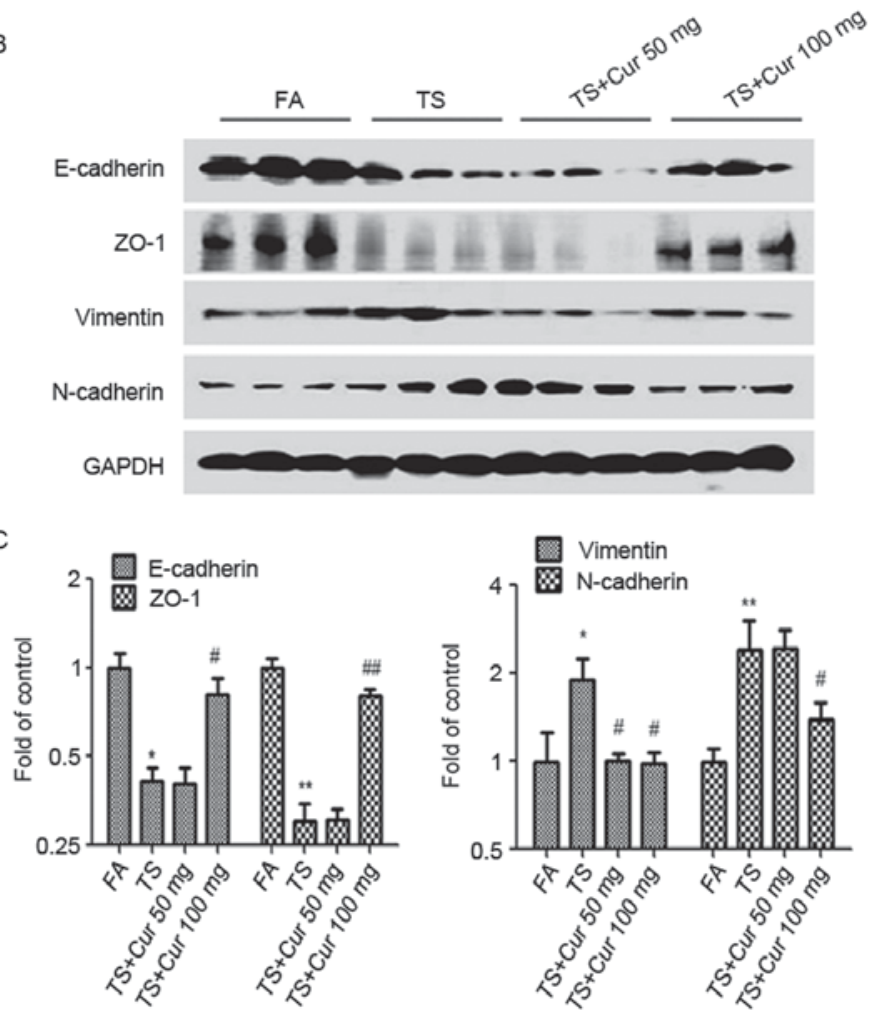

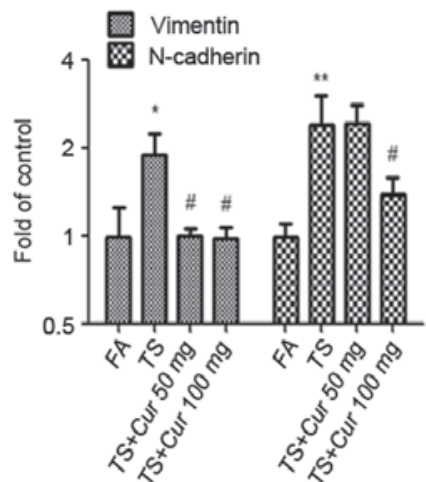

Figure 3. Curcumin reversed TS-induced pulmonary epithelial-mesenchymal transition alterations in mice. (A) mRNA expression of E-cadherin, ZO-1, vimentin and $\mathrm{N}$-cadherin, as determined by reverse transcription-quantitative polymerase chain reaction. (B) Western blot analysis of E-cadherin, ZO-1, vimentin and $\mathrm{N}$-cadherin protein expression. GAPDH was used as a loading control. (C) Densitometric analysis of western blot results. Data are presented as the mean \pm standard deviation. ${ }^{*} \mathrm{P}<0.05$ and ${ }^{* *} \mathrm{P}<0.01$ vs. FA; ${ }^{\# P}<0.05$ and ${ }^{\# \#} \mathrm{P}<0.01$ vs. TS-only group. TS, tobacco smoke; $\mathrm{ZO}$, zona occludens; FA, filtered air; Cur, curcumin.
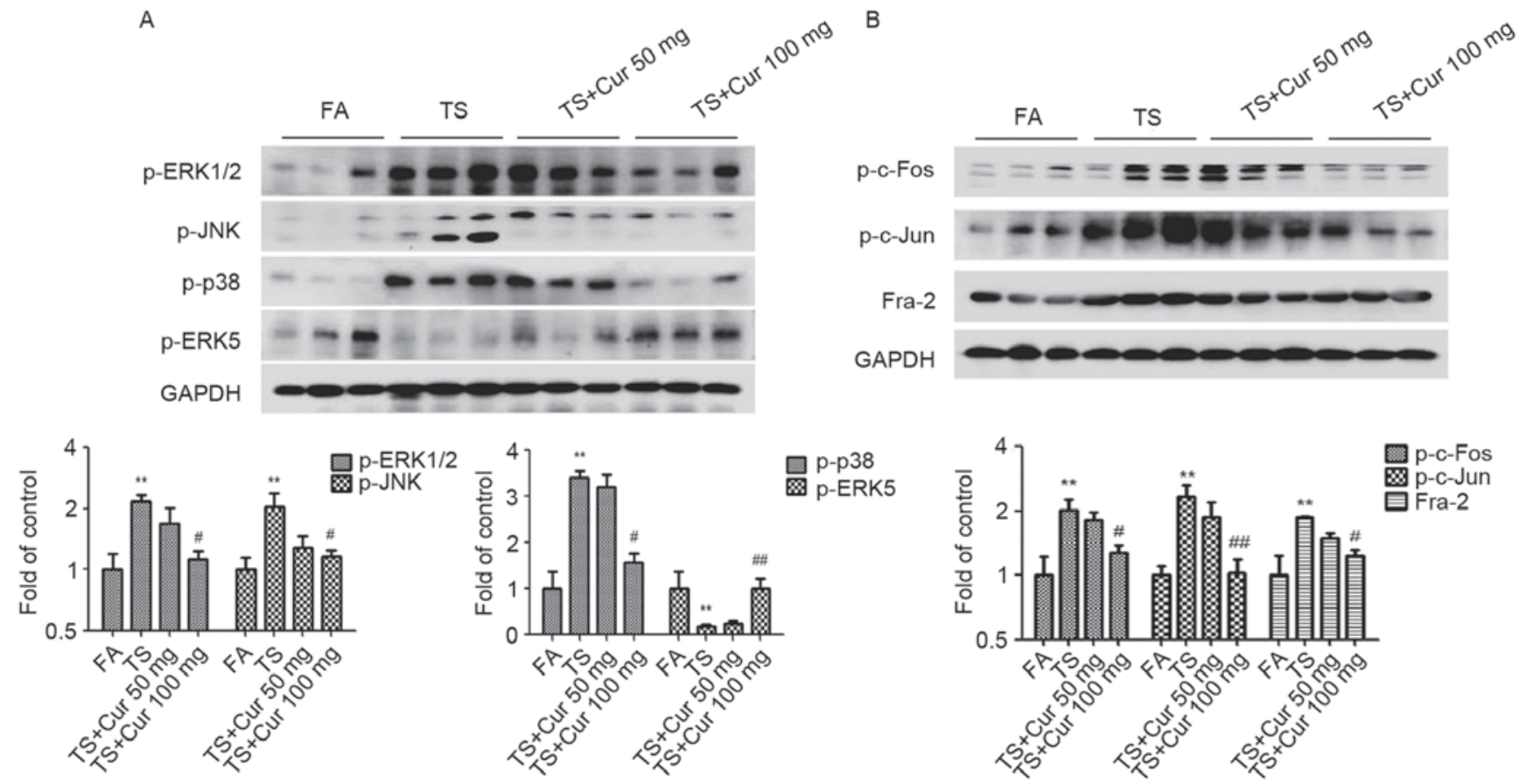

Figure 4. Curcumin altered TS-induced MAPK/AP-1 activation in the lungs of mice. (A) p-ERK1/2, p-JNK, p-p38 and p-ERK5 protein expression by western blotting. (B) Western blot analysis of p-c-Fos, p-c-Jun and Fra- 2 . Data are presented as the mean \pm standard deviation. ${ }^{* *} \mathrm{P}<0.01$ vs. FA; ${ }^{\#} \mathrm{P}<0.05$ and ${ }^{\# \#} \mathrm{P}<0.01 \mathrm{vs}$. TS-only group. TS, tobacco smoke; MAPK, mitogen-activated protein kinase; AP-1, activator protein-1; p-, phosphorylated-; ERK, extracellular-signal-regulated kinase; JNK, c-Jun N-terminal kinase; Fra-2, Fos-like 2 AP-1 transcription factor subunit; FA, filtered air; Cur, curcumin.

Curcumin attenuates tobacco smoke-induced pulmonary MAPK alterations. To gain an improved understanding of the influence of curcumin on tobacco smoke-mediated pulmonary activation of the MAPK/AP-1 pathways, the changes in 
MAPK/AP-1 activation following curcumin treatment were examined. Western blot analysis revealed that curcumin (100 mg/kg BW) suppressed tobacco smoke-induced ERK1/2, p38 and JNK activation, and increased ERK5 activation in the lung tissues of mice exposed to tobacco smoke (Fig. 4A). The results also demonstrated that treatment with $100 \mathrm{mg} / \mathrm{kg}$ BW curcumin significantly decreased tobacco smoke-induced AP-1 activation, as indicated by reduced expression of p-c-Fos, p-c-Jun and Fra-2 compared with the tobacco smoke-treated group without curcumin treatment (Fig. 4B).

\section{Discussion}

Lung cancer is the leading cause of cancer-associated mortality globally. Studies have confirmed the association between the occurrence of lung cancer and tobacco smoke $(33,34)$. As a major contributor to lung cancer, tobacco smoke promotes the initiation and progression of lung cancer. However, further investigation of the mechanisms involved in the initiation and development of lung cancer induced by tobacco smoke is required. The present study demonstrated that EMT alterations were induced by tobacco smoke in the lungs of mice. It further revealed that the activation of MAPK pathways was implicated in tobacco smoke-induced lung EMT, in addition to AP-1 activation. Furthermore, the results indicated that curcumin treatment prevented tobacco smoke-induced lung EMT changes and MAPK/AP-1 activation in vivo.

EMT serves an important role in cancer initiation and development. The exposure of cells to carcinogens has been reported to induce EMT during transformation and tumor formation (35-39), indicating that EMT, by promoting cell malignancy transformation, may be associated with the initiation of tumorigenesis. The results of the present study were consistent with these reports, as they demonstrated that, following exposure to tobacco smoke for 12 weeks, tobacco alterations in EMT were observed in the lungs of mice. Tobacco smoke exposure decreased the expression of the epithelial markers E-cadherin and ZO-1, and increased the expression of the mesenchymal markers vimentin and $\mathrm{N}$-cadherin. These results indicate that tobacco smoke may induce lung EMT in vivo.

EMT alterations are associated with various cell signaling pathways. MAPK pathways are reported to promote the initiation and progression of cancer, and are therefore important in the tumorigenic process (40). Studies have demonstrated that p38, ERK1/2 and JNK promote EMT $(16,17,41)$. However, the role of ERK5 in EMT regulation has not been well characterized. The present study identified that tobacco smoke upregulated p38, ERK1/2 and JNK, thus inducing lung EMT in vivo. However, it was also demonstrated that tobacco smoke downregulated ERK5 activation, which was consistent with our previous findings (20,21). Furthermore, the present study also demonstrated that tobacco smoke-induced EMT was associated with increased activation of AP-1. These results indicate that tobacco smoke-induced lung EMT may be associated with MAPK/AP-1 activation.

Curcumin is a turmeric-derived active component that has been widely used in medicine in India and Southeast Asia (42). It has been used as a chemopreventive agent against a number of tumors due to its anticancer functions. The safety and anticancer activities of curcumin have been reported in various cancers $(43,44)$. In the present study, BALB/c mice were treated with curcumin at 50 and $100 \mathrm{mg} / \mathrm{kg}$ BW/day. These concentrations were selected as they proved to be efficient in other animal studies $(31,45)$. These doses are equivalent to a human dose of 3-6 g/day per adult (46). Following curcumin and tobacco smoke treatment for 12 weeks, changes in the mRNA and protein expression of EMT markers were examined, and the results indicated that the expression of the epithelial markers ZO-1 and E-cadherin was downregulated, while the expression of the mesenchymal markers $\mathrm{N}$-cadherin and vimentin was upregulated, in mice treated with tobacco smoke compared with those treated with filtered air. Furthermore, curcumin (100 mg/kg BW/day) markedly attenuated tobacco smoke-induced EMT alterations in the lungs of mice. It was also demonstrated that treatment with curcumin at $100 \mathrm{mg} / \mathrm{kg}$ BW suppressed tobacco smoke-induced activation of JNK, ERK1/2 and p38 MAPK pathways, in addition to AP-1 activation. Thus, the results of the present study indicate that the curcumin-mediated protective effect against tobacco smoke-induced pulmonary EMT changes may occur via MAPK/AP-1 pathways.

In conclusion, the present study demonstrated that curcumin treatment effectively attenuated tobacco smoke-induced MAPK activation and EMT changes in lung tissue. These data may provide novel insights into the molecular pathogenesis and chemoprevention of tobacco smoke-associated lung cancer.

\section{Acknowledgements}

The present study was supported by grants from the National Natural Science Foundation of China (grant nos. 81602883, 81373005 and 81072330), the National Basic Research Program of China (973 Program; grant no. 2013CB910303) and the China Postdoctoral Science Foundation Funded Project (grant no. 2016M591792).

\section{References}

1. Jemal A, Siegel R, Xu J and Ward E: Cancer statistics, 2010. CA Cancer J Clin 60: 277-300, 2010.

2. Siegel R, Ma J, Zou Z and Jemal A: Cancer statistics, 2014. CA Cancer J Clin 64: 9-29, 2014.

3. Chen W, Zheng R, Zeng H, Zhang S and He J: Annual report on status of cancer in China, 2011. Chin J Cancer Res 27: 2-12, 2015.

4. Agudo A, Bonet C, Travier N, González CA, Vineis P, Bueno-deMesquita HB, Trichopoulos D, Boffetta P, Clavel-Chapelon F, Boutron-Ruault MC, et al: Impact of cigarette smoking on cancer risk in the European prospective investigation into cancer and nutrition study. J Clin Oncol 30: 4550-4557, 2012.

5. IARC Working Group on the Evaluation of Carcinogenic Risks to Humans: Tobacco smoke and involuntary smoking. IARC Monogr Eval Carcinog Risks Hum 83: 1-1438, 2004.

6. Breheny D, Cunningham F, Kilford J, Payne R, Dillon D and Meredith C: Application of a modified gaseous exposure system to the in vitro toxicological assessment of tobacco smoke toxicants. Environ Mol Mutagen 55: 662-672, 2014.

7. Li LF, Chan RL, Lu L, Shen J, Zhang L, Wu WK, Wang L, Hu T, $\mathrm{Li} \mathrm{MX}$ and Cho $\mathrm{CH}$ : Cigarette smoking and gastrointestinal diseases: The causal relationship and underlying molecular mechanisms (Review). Int J Mol Med 34: 372-380, 2014.

8. Tam WL and Weinberg RA: The epigenetics of epithelial-mesenchymal plasticity in cancer. Nat Med 19: 1438-1449, 2013.

9. Nieto MA: Epithelial plasticity: A common theme in embryonic and cancer cells. Science 342: 1234850, 2013.

10. Rhim AD: Epithelial to mesenchymal transition and the generation of stem-like cells in pancreatic cancer. Pancreatology 13: 114-117, 2013. 
11. Pinto CA,WidodoE,Waltham Mand ThompsonEW: Breast cancer stem cells and epithelial mesenchymal plasticity-implications for chemoresistance. Cancer Lett 341: 56-62, 2013.

12. Wang Q, Wang Y, Zhang Y, Zhang Y and Xiao W: Involvement of urokinase in cigarette smoke extract-induced epithelial-mesenchymal transition in human small airway epithelial cells. Lab Invest 95: 469-479, 2015.

13. Eurlings IM, Reynaert NL, van den Beucken T, Gosker HR, de Theije CC, Verhamme FM, Bracke KR, Wouters EF and Dentener MA: Cigarette smoke extract induces a phenotypic shift in epithelial cells; involvement of HIF1 $\alpha$ in mesenchymal transition. PLoS One 9: e107757, 2014.

14. Jalmi SK and Sinha AK: ROS mediated MAPK signaling in abiotic and biotic stress-striking similarities and differences. Front Plant Sci 6: 769, 2015.

15. Khavari TA and Rinn J: Ras/Erk MAPK signaling in epidermal homeostasis and neoplasia. Cell Cycle 6: 2928-2931, 2007.

16. Wang J, Li JZ, Lu AX, Zhang KF and Li BJ: Anticancer effect of salidroside on A549 lung cancer cells through inhibition of oxidative stress and phospho-p38 expression. Oncol Lett 7: $1159-1164,2014$

17. Li T, Zhang C, Ding Y, Zhai W, Liu K, Bu F, Tu T, Sun L, Zhu W, Zhou F, et al: Umbilical cord-derived mesenchymal stem cells promote proliferation and migration in MCF-7 and MDA-MB-231 breast cancer cells through activation of the ERK pathway. Oncol Rep 34: 1469-1477, 2015.

18. Liang Z, Xie W, Wu R, Geng H, Zhao L, Xie C, Li X, Zhu M, Zhu W, Zhu J, et al: Inhibition of tobacco smoke-induced bladder MAPK activation and epithelial-mesenchymal transition in mice by curcumin. Int J Clin Exp Pathol 8: 4503-4513, 2015.

19. Liang Z, Wu R, Xie W, Geng H, Zhao L, Xie C, Wu J, Geng S, $\mathrm{Li}$ X, Zhu M, et al: Curcumin suppresses MAPK pathways to reverse tobacco smoke-induced gastric epithelial-mesenchymal transition in mice. Phytother Res 29: 1665-1671, 2015.

20. Liang Z, Xie W, Wu R, Geng H, Zhao L, Xie C, Li X, Huang C, Zhu J, Zhu M, et al: ERK5 negatively regulates tobacco smoke-induced pulmonary epithelial-mesenchymal transition. Oncotarget 6: 19605-19618, 2015.

21. Lu L, Chen J, Tang H, Bai L, Lu C, Wang K, Li M, Yan Y, Tang L, Wu R, et al: EGCG suppresses ERK5 activation to reverse tobacco smoke-triggered gastric epithelial-mesenchymal transition in BALB/c mice. Nutrients 8: pii: E380, 2016

22. Toda S, Miyase T, Arichi H, Tanizawa $\mathrm{H}$ and Takino $\mathrm{Y}$ : Natural antioxidants. III. Antioxidative components isolated from rhizome of Curcuma longa L. Chem Pharm Bull (Tokyo) 33 1725-1728, 1985.

23. Satoskar RR, Shah SJ and Shenoy SG: Evaluation of anti-inflammatory property of curcumin (diferuloyl methane) in patients with postoperative inflammation. Int J Clin Pharmacol Ther Toxicol 24: 651-654, 1986.

24. Sidhu GS, Singh AK, Thaloor D, Banaudha KK, Patnaik GK, Srimal RC and Maheshwari RK: Enhancement of wound healing by curcumin in animals. Wound Repair Regen 6: 167-177, 1998.

25. Negi PS, Jayaprakasha GK, Jagan Mohan Rao L and Sakariah KK Antibacterial activity of turmeric oil: A byproduct from curcumin manufacture. J Agric Food Chem 47: 4297-4300, 1999.

26. Aggarwal BB, Sundaram C, Malani N and Ichikawa H: Curcumin: The indian solid gold. Adv Exp Med Biol 595: 1-75, 2007.

27. Saha S, Adhikary A, Bhattacharyya P, Das T and Sa G: Death by design: Where curcumin sensitizes drug-resistant tumours. Anticancer Res 32: 2567-2584, 2012.

28. Aggarwal BB and Harikumar KB: Potential therapeutic effects of curcumin, the anti-inflammatory agent, against neurodegenerative, cardiovascular, pulmonary, metabolic, autoimmune and neoplastic diseases. Int J Biochem Cell Biol 41: 40-59, 2009.

29. Maheshwari RK, Singh AK, Gaddipati J and Srimal RC: Multiple biological activities of curcumin: A short review. Life Sci 78: 2081-2087, 2006.
30. Gonçalves Vde P, Ortega AA, Guimarães MR, Curylofo FA, Rossa Junior C, Ribeiro DA and Spolidorio LC: Chemopreventive activity of systemically administered curcumin on oral cancer in the 4-nitroquinoline 1-oxide model. J Cell Biochem 116: 787-796, 2015.

31. Okamoto Y, Pehlivan D, Wiszniewski W, Beck CR, Snipes GJ, Lupski JR and Khajavi M: Curcumin facilitates a transitory cellular stress response in Trembler-J mice. Hum Mol Genet 22: 4698-4705, 2013.

32. Livak KJ and Schmittgen TD: Analysis of relative gene expression data using real-time quantitative PCR and the 2(-Delta Delta C(T)) method. Methods 25: 402-408, 2001.

33. Chen Z, Peto R, Zhou M, Iona A, Smith M, Yang L, Guo Y, Chen Y, Bian Z, Lancaster G, et al: Contrasting male and female trends in tobacco-attributed mortality in China: Evidence from successive nationwide prospective cohort studies. Lancet 386 : 1447-1456, 2015.

34. Pandeya N, Wilson LF, Bain CJ, Martin KL, Webb PM and Whiteman DC: Cancers in Australia in 2010 attributable to tobacco smoke. Aust N Z J Public Health 39: 464-470, 2015.

35. Yue H, Yun Y, Gao R, Li G and Sang N: Winter polycyclic aromatic hydrocarbon-bound particulate matter from peri-urban North China promotes lung cancer cell metastasis. Environ Sci Technol 49: 14484-14493, 2015.

36. Yeo CD, Kim JW, Ha JH, Kim SJ, Lee SH, Kim IK and Kim YK: Chemopreventive effect of phosphodieasterase-4 inhibition in benzo (a)pyrene-induced murine lung cancer model. Exp Lung Res 40: 500-506, 2014.

37. Luo F, Ji J, Liu Y, Xu Y, Zheng G, Jing J, Wang B, Xu W, Shi L, Lu X and Liu Q: MicroRNA-21, up-regulated by arsenite, directs the epithelial-mesenchymal transition and enhances the invasive potential of transformed human bronchial epithelial cells by targeting PDCD4. Toxicol Lett 232: 301-309, 2015.

38. Chen ZJ, Yang XL, Liu H, Wei W, Zhang KS, Huang HB, Giesy JP, Liu HL, Du J and Wang HS: Bisphenol A modulates colorectal cancer protein profile and promotes the metastasis via induction of epithelial to mesenchymal transitions. Arch Toxicol 89: 1371-1381, 2015.

39. Mennecier G, Torres LN, Cogliati B, Sanches DS, Mori CM, Latorre AO, Chaible LM, Mackowiak II, Nagamine MK, Da Silva TC, et al: Chronic exposure of lung alveolar epithelial type II cells to tobacco-specific carcinogen NNK results in malignant transformation: A new in vitro lung carcinogenesis model. Mol Carcinog 53: 392-402, 2014

40. Masliah-Planchon J, Garinet S and Pasmant E: RAS-MAPK pathway epigenetic activation in cancer: miRNAs in action. Oncotarget 7: 38892-38907, 2016.

41. Cellurale C, Sabio G, Kennedy NJ, Das M, Barlow M, Sandy P, Jacks T and Davis RJ: Requirement of c-Jun NH (2)-terminal kinase for Ras-initiated tumor formation. Mol Cell Biol 31: 1565-1576, 2011.

42. Patel PB, Thakkar VR and Patel JS: Cellular effect of curcumin and citral combination on breast cancer cells: Induction of apoptosis and cell cycle arrest. J Breast Cancer 18: 225-234, 2015.

43. Kunnumakkara AB, Anand P and Aggarwal BB: Curcumin inhibits proliferation, invasion, angiogenesis and metastasis of different cancers through interaction with multiple cell signaling proteins. Cancer Lett 269: 199-225, 2008.

44. Anand P, Sundaram C, Jhurani S, Kunnumakkara AB and Aggarwal BB: Curcumin and cancer: An 'old-age' disease with an 'age-old' solution. Cancer Lett 267: 133-164, 2008.

45. Sun LN, Chen ZX, Liu XC, Liu HY, Guan GJ and Liu G: Curcumin ameliorates epithelial-to-mesenchymal transition of podocytes in vivo and in vitro via regulating caveolin-1. Biomed Pharmacother 68: 1079-1088, 2014.

46. Anand P, Kunnumakkara AB, Newman RA and Aggarwal BB: Bioavailability of curcumin: Problems and promises. Mol Pharm 4: 807-818, 2007. 